\title{
The Science and Technology of Cancer Theranostic Nanomedicines: a primer for Clinicians and Pharmacists
}

\author{
Gopalakrishna Pillai*, Arthur Cox and Le Yuen \\ Department of Pharmaceutical Sciences, Sullivan University College of Pharmacy, Louisville, KY, USA
}

Received: March 16, 2018; Accepted: April 19, 2018; Published: April 26, 2018

*Corresponding author: Gopalakrishna Pillai, Department of Pharmaceutical Sciences, Sullivan University College of Pharmacy, 2100 Gardiner Lane, Louisville, KY, USA, E-mail: Gpillai@sullivan.edu

\begin{abstract}
The term "theranostics" refers to simultaneous diagnostic imaging and treatment and "nanotheranostics" refers to the simultaneous diagnostic imaging and treatment that makes use of nanomaterials for selective delivery of an imaging agent and a chemotherapeutic agent to a target organ. Nanocarriers have special properties that make them suitable for design of the theranostic platform. These include enhanced permeation and retention (the EPR effect), the provision for active targeting by attachment of suitable ligands to their surface, and unique optical and magnetic properties. Advanced theranostic systems are multifunctional in that the nanocarrier contains a homing device or targeting agent that directs the carrier to the cancer tissue, an agent for imaging the cancer tissue, and a chemotherapeutic agent to be delivered selectively to the tumor. The core nanomaterial is often surface-modified to facilitate incorporation of the various functionalities. Several types of nanoparticles (NPs) have been employed as imaging and drug delivery agents, including both solid inorganic materials $\left(\mathrm{Fe}_{3} \mathrm{O}_{4} \mathrm{NPs}\right.$, Gadolinium NPs, Gold NPs, carbon nanotubes, semiconductor quantum dots) and organic-based NPs, including liposomes, micelles, dendrimers and polymers. The nanotheranostic platform is capable of simultaneous imaging and therapy, as seen in the case of gold nanoparticles. Gold NPs can generate heat when irradiated with light of a specific wavelength, which can kill tumor cells due to hyperthermia. The high atomic number of gold and its X-ray absorption allows simultaneous tumor imaging via the fluorescence quenching effect or by computed tomography. Other methods of imaging such as Magnetic Resonance Imaging (MRI), Positron Emission Tomography (PET), fluorescence and ultrasound may also be employed depending on the properties of the nanomaterial, while the tumor killing agent (drug, genes or hyperthermia) is being delivered selectively to the tumor. Molecular imaging can identify the location of the tumor cell within the body as well as provide information about the expression profile and stage of the disease. It can also reveal early tumor response to therapy that will facilitate determination of treatment regimens. Therefore, the incorporation of both diagnostic and therapeutic modalities onto the same nanomaterial is a promising strategy to improving the efficiency and safety of drug delivery systems. This review will focus on the basic science and technology involved in the design and development of Nano platforms capable of simultaneous delivery of diagnostic imaging agents and cancer therapeutic agents.
\end{abstract}

Key words: Theranostics; Nanocarriers; Nanomedicine; Diagnostic Imaging; Inorganic NPs; Gold NPs; Magnetic NPs; Quantum dots;

Carbon nanotubes; MRI/CT/Fluorescence

\section{Introduction}

The term "theranostics" refers to simultaneous diagnostic imaging and treatment and "nanotheranostics" refers to the simultaneous diagnostic imaging and treatment that make use of nanomaterials for selective delivery of a diagnostic imaging agent and a chemotherapeutic agent to a target organ. The basic principles of theranostics have been in practice since the 1940s with the use of radioiodine to image and treat thyroid cancers. Theranostic tests differ from traditional diagnostic tests such as those for blood glucose, because the new tests are based on sophisticated technology that involves principles of genetics, molecular biology and special testing platforms. Advances in these areas have provided biochemical information about cancers, including the identification of many cell surface receptors which are over expressed in tumor cells. Theranostics takes advantage of these molecular targets to gain access to the tumors and in visualizing and delivering cytotoxic drugs directly to the tumor. Therefore, diagnostics and therapy work hand-in-hand for the benefit of the cancer patients.
Advanced theranostic nanomedicine is multifunctional in nature. The nanomaterial carrier contains an agent for imaging, a homing device (targeting agent) that takes the system to the tumor, and an anticancer agent to be delivered to the tumor. Therefore, the nanotheranostic system itself is capable of simultaneous imaging and therapy. For example, gold NPs can image a tumor via fluorescent quenching or computed tomography (CT), while simultaneously killing tumor cells by generating heat when irradiated with light of a specific wavelength. CT is possible because of the high atomic number of gold and its X-ray absorption. Other methods of imaging such as Magnetic Resonance Imaging (MRI), Positron Emission Tomography (PET), fluorescence and ultrasound may also be employed, depending on the properties of the nanomaterial, while the tumor killing agent (drug or hyperthermia) is being delivered selectively to the tumor.

\section{Why Nano carriers for theranostics?}

The prefix "nano" originally came from the Greek word "nanos", meaning dwarf. In scientific usage "nanometer" means 
one billionth of a meter. One nanometer is the length of ten hydrogen atoms placed side by side. Cesium, the largest known atom has a diameter of $0.53 \mathrm{~nm}$. The size of some familiar materials in the nanoworld is: DNA, 1-2nm diameter; viruses, 3-50 nm; insulin molecule, $3 \mathrm{~nm}$ and cytochrome, $4 \mathrm{~nm}$. One million fullerenes, the smallest "soccer ball" made from 60 carbon atoms, can fit into a grain of rice. Materials in the nanosize range can exhibit very different behavior compared to their macro or bulk material. The mechanical strength, electrical conductivity, color, reactivity, and melting point are subject to change following a size reduction. At the nanoscale, Carbon is stronger than steel and six times lighter. White and opaque zinc oxide becomes transparent, thus cosmetically appealing, and a gold colloid less than $100 \mathrm{~nm}$ are no more 'golden' but appears intensely red. The same gold colloid will appear blue when the particle size is above $100 \mathrm{~nm}$. Nanoparticles also have relatively huge surface areas per unit mass (upwards of $1000 \mathrm{~m}^{2} / \mathrm{g}$ ); a property that leads to unexpected reactivity compared to their macro counterparts. Most of the atoms of nanoscale materials will reside on the surface, hence the increased reactivity of nanomaterials. As the particle gets smaller and smaller, their surface area to volume ratio increases dramatically. They are more reactive and more soluble in water. In contrast to macroscopic materials, nanomaterials have tunable optical, electronic, magnetic, thermal and biologic properties. The optical properties are exploited for imaging by various spectroscopic techniques. For example, "quantum dots" (QDs) which are inorganic semiconductor materials with a very bright fluorescence, can be used for fluorescence imaging with high sensitivity and selectivity. The magnetic properties of some inorganic nanoparticles (NPs) such as paramagnetic iron oxide $\left(\mathrm{Fe}_{3} \mathrm{O}_{4}\right)$ lead to their use in enhancing imaging quality by magnetic resonance (MRI). Gold nanoparticles when irradiated with light of certain wavelength generate enough heat to be lethal for tumor cells. This property is exploited for the photothermic therapy (hyperthermia), by delivering heat directly to tumor cells without damaging healthy cells. Surface modifications of NPs can be made to increase circulation time in the blood. For instance, the NPs can be coated with a hydrophilic polymer such as polyethylene glycol (PEG). This common technique, called PEGylation, results in increased circulation time because the NPs are not taken up through phagocytosis by the mononuclear phagocyte system (MPS), and therefore more drugs can accumulate in the tumor. The Enhanced Permeation and Retention (EPR) effect, combined with longer circulation time, results in concentration of drugs in the tumor by 10-100 times compared to the free drug [1]. NPs are excellent molecular transporters that can simultaneously improve solubility of hydrophobic drugs and protect them from metabolism, while improving localized drug delivery. Furthermore, nanoparticles have a high surface area to volume ratio, giving them high loading capacity for imaging probes, targeting ligands and therapeutic molecules. Multifunctionality is the key advantage of nanoplatfoms over traditional approaches to imaging and drug delivery. Targeting ligands, imaging labels, therapeutic drugs, and many other agents can all be integrated into one nanoplatform, permitting targeted molecular imaging and molecular therapy [2-6]. Furthermore, nanomedicines can deliver drugs at higher doses with lower side effects, either by passive delivery from the EPR effect of newly-developed capillaries supplying blood and nutrients to the tumor or through receptor-mediated active targeting [5, 7-8]. Another advantage of nano imaging is the potential to detect and diagnose cancer at an earlier stage than with current imaging methods [9]. For example, iron oxide particles $10 \mathrm{~nm}$ diameters coated with polymer and urokinase plasminogen activator (UPA) have been demonstrated to be effective in this regard. The uPA protein on the particles binds to its receptor (UPAR) on pancreatic cancer cells, resulting in selective uptake by the cancer cells and not by normal pancreatic tissue. With these system tumors as small as $1 \mathrm{~mm}$ could be detected by MRI or optical imaging [10]. Several types of NPs have been employed as imaging and delivery agents, including both solid inorganic materials (Iron oxide $\left(\mathrm{Fe}_{3} \mathrm{O}_{4}\right)$ NPs, Gadolinium NPs, Gold NPs, carbon nanotubes, semiconductor quantum dots) and organic-based NPs, including liposomes, micelles, dendrimers and polymers.

\section{Inorganic NPs-based theranostics}

Inorganic NPs consist of magnetic metal oxide, metallic, or semiconductor materials. Synthetic methods are now available for surface functionalization of inorganic NPs to introduce targeting ligands and therapeutic molecules for molecular imaging and therapy [11]. For example, Ferric oxide $\left(\mathrm{Fe}_{3} \mathrm{O}_{4}\right)$ NPs are synthesized by reduction of an iron precursor under an inert atmosphere with a source of reactive oxygen at high temperatures $[12,13]$. Further modification of the surface is also necessary to facilitate attachment of the required ligands. This can include incorporation of an amino- or carboxyfunctional group or a hydrophilic agent. Other metal oxide NPs such as gadolinium oxide and semiconductor quantum dots are prepared by similar approaches [14-15]. Inorganic NPs can also be prepared by co-precipitation methods involving precipitation of the metal ions with a corresponding counter ion in solution as well as by microemulsion methods [16-17].

\section{Gold nanoparticles-based theranostics}

Of the numerous metallic nanoparticles, gold NPs are considered to have the highest potential for biomedical applications because of their low toxicity, biocompatibility, and unique surface characteristics. These surface characteristics are amenable to functionalization, having the ability to bind amine and thiol groups. Gold NPs are therefore being investigated as drug carriers, photothermal agents, contrast agents, and as photosensitizers. One of the methods of preparing gold NPs is to reduce a gold $3+$ salt with sodium citrate solution to metallic gold. Formation of a ruby red color is an indication of formation of colloidal gold. Gold NPs can be prepared in various sizes and shapes including nanospheres, nanorods, hollow nanospheres, nanostars, nanocages and nanorings. The hollow gold nanospheres (20-70 nm) have some interesting advantages: while the absorption peak of gold nanospheres is in the visible 
Plasmon resonance: The changes in size and shape of gold nanoparticles cause a shift in surface plasmon resonance, which accounts for the optical and thermal properties useful for theranostics. When excited with specific laser energy, gold-based nanomaterials produce high temperatures useful for destruction of the tumor, referred to as photothermic tissue ablation. Such a modality is especially useful for tissues that are not readily removed by surgery. The resonance bands can be further tuned towards the near infrared region (NIR) for deep penetration into the tissues without interference from absorption by the tissue components.

region, the absorption peak of the hollow nanospheres can be adjusted to near infra-red (700-900 $\mathrm{nm})$.

in biological tissues due to lack of absorption of IR light by tissue components. This property facilitates photothermal therapy using near IR lasers. In addition, the hollow NPs can be used for high loading of drugs and other ligands [18]. Encapsulating other materials such as iron oxide in the hollow gold NPs has the advantage of combining the magnetic properties of iron oxide and the plasmon resonance of Gold NPs near the infrared region into one nanoparticle [19]. Moreover, hollow gold nanospheres are more effective at absorbing near infrared light than solid gold NPs. The absorption is not only strong but is also narrow and tunable. All of these properties are important for cancer imaging and treatment. The Gold NPs do not have to be spheres, but can also be used as nanorods [20].

Another important property of gold nanoparticles (GNPs) that makes them suitable for delivery of cancer therapy is their facile surface functionalization utilizing the reactivity of the thiol group [21,22]. One of the functionalization methods involves the substitution of a citrate group on the GNP by thiolated ligands (Figure 1).

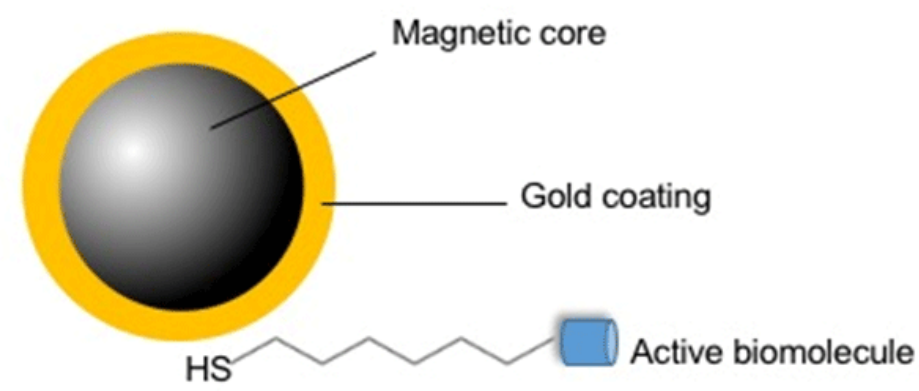

Figure 1: Gold-coated NP surface functionalization via thiol group

This approach has been used to attach a wide range of ligands to GNPs including PEG, fluorescent dyes and drugs such as paclitaxel. Paclitaxel, for example, is attached to the surface of gold nanoparticles along with biotin receptor for diagnosis and treatment [23]. A variation of this approach is the formation of an inclusion complex with beta cyclodextrin-conjugated gold nanoparticles which is also linked to biotin and rhodamine $B$, from which the drug is effectively released by intracellular glutathione [24]. The potential of gold NPs coated with tumor necrosis factor alpha (TNF- $\alpha$ ) for photothermal ablation of tumors has been demonstrated in mice by Shao et al. [25]. TNF- $\alpha$ is a potent, multifunctional cytokine that exhibits anticancer properties. However, direct use results in systemic toxicity due to the indiscriminate actions on both normal and malignant tissues. In contrast to the native TNF, TNF conjugated to a thiol-derivatized PEG gold nanoplatform is efficient in reducing tumor burden without the toxicity. TNF-gold NPs is now in phase 2 trials in humans. Gold nanoparticles also have effective fluorescent-quenching capabilities that can be utilized to detect specific molecular biomarkers. In addition, Gold NPs can be utilized as imaging agents in computed tomography because of their high atomic number and x-ray absorption coefficient. They are also used as contrast agents for photoacoustic imaging. 


\section{PET scan}

The positron emission tomography (PET) scan creates computerized images when chemical changes, such as sugar metabolism, take place in a tissue. Typically, the patient is given an injection of a substance that consists of a combination of a sugar and a small amount of radioactively labeled sugar that emits positrons (18F-fluorodeoxyglucose, most commonly used oncologic PET tracer). 18F has a half-life of 110 minutes which is convenient for transportation from the cyclotron and compatible with the whole-body imaging time of about 30minutes. The PET scanner detects the position of the radioactive tracer and the cancer cells (area of hyper metabolism) since cancer cells take up or absorb sugar more avidly than other tissues.

\section{PET/CT}

This combination provides complimentary information. While PET provide functional detail but little anatomic detail, CT provide anatomic and morphologic information (size, shape, location and density of lesions), but provides little insight into a tissue's physiological status. Attachment of a radionuclide on a high density NP could provide both the high sensitivity of PET along with anatomical localization with CT in a single theranostic agent. PET/CT imaging platforms have been commercially available for many years and are routinely used for early detection of cancer recurrence and localization.

\section{SPECT Scan}

Like PET, Single Photon Emission Computed Tomography (SPECT) uses radioactive tracers and a scanner to record data from which a computer constructs two- or three-dimensional images. A small amount of a radioactive drug is injected into a vein and a scanner is used to make detailed images of areas inside the body where the radioactive material is taken up by the cells. SPECT can give information about blood flow to tissues and chemical reactions (metabolism) in the body. In this procedure, antibodies (proteins that recognize and stick to tumor cells) can be linked to a radioactive substance. If a tumor is present, the antibodies will stick to it. Then a SPECT scan can be done to detect the radioactive substance and reveal where the tumor is located.

\section{Magnetic resonance imaging (MRI)}

TMRI is based upon the science of Nuclear Magnetic Resonance (NMR). Certain atomic nuclei, including hydrogen, are abundant in body water and fat and can absorb and emit radiofrequency (RF) energy when placed in an external magnetic field. The hydrogen atoms align themselves in a strong magnetic field by a change of the spin of electrons, like the needle of a compass. Pulses of specific radiofrequencies are then used to bring back the hydrogen atoms to original state. All nuclei relax by two relaxation mechanisms: T1 (spin-lattice relaxation) and T2 (spinspin relaxation). In the presence of MRI contrast agents, the relaxation time of protons in tissues change, which is detected by MRI. The MRI equipment records the duration, strength and source of the signals emitted during the relaxation process of the hydrogen atoms. The signals are then translated to an image. Agents such as gadolinium are used to improve the contrast of the signals between diseased and healthy tissues. The image and resolution produced by MRI is quite detailed and can detect small changes of structures within the body. Gadolinium chelates are currently the MRI contrast agents of choice because the gadolinium (III) ion is the best known T1 contrast agent due to its large magnetic moment [26]. Gadolinium NPs with sizes ranging from 1 to $3 \mathrm{~nm}$ have been shown to be the best at increasing both the relaxation and contrast enhancement properties.

Iron oxide NPs are superparamagnetic (SPION). They are used for T2 MRI [27-29]. The strength of the individual imaging modalities may be combined for tri-modal imaging with MRI, CT and fluorescence. This can achieve better temporal and spatial resolution with increased sensitivity. For example, PEG-coated gold/silica NPs that have a fluorescent dye and paramagnets provide contrast in CT, MRI and optical imaging.

\section{Photoacoustic imaging (PA imaging)}

Photoacoustic methods take advantage of the surface plasmonic resonance property of gold and silver nanoparticles. Upon laser irradiation, this can give rise to heat, which ultimately generates the pressure waves that form the photoacoustic signal. The efficiency of acoustic signal generation is high because of the large absorption cross section of metal nanoparticles and negligible radiative relaxation. These optothermal properties have been the basis for the development of metal nanoparticles as contrast agents for photoacoustic imaging. With PA imaging it is possible to obtain information about the anatomical, functional and molecular content of a diseased tissue without the use of ionizing radiation. Compared to fluorescence imaging, PA imaging has better spatial resolution and deeper imaging depth. It gives better tissue contrast than ultrasound imaging. PA imaging is safer than CT or PET because no ionizing radiation is used.

\section{Raman spectroscopy}

Raman spectroscopy is most sensitive to highly symmetric covalent bonds with little or no natural dipole moment. The carbon-carbon bonds that make up these materials fit this criterion perfectly, and as a result Raman spectroscopy is highly sensitive to these materials and able to provide a wealth of information about their structure. Raman spectroscopy is capable of discerning even slight changes in structure, making it a very valuable tool in the characterization of carbon nanomaterials. 
Gold NPs functionalized with a prostate-specific membrane antigen (PSMA) aptamer that binds specifically to PSMA are useful for specific imaging of prostate cancer cells that express PSMA. The conjugate showed more than 4-fold greater CT intensity than that of non-targeted pc-3 cells. Doxorubicin was also conjugated to this system which has shown greater potency against pc3 cells [30]. Other imaging modalities also have been investigated using Gold NPs such as light scattering, Raman spectroscopy, photoacoustic imaging and MRI [31-34].

\section{Magnetic nanoparticles-based theranostics}

The most studied magnetic nanoparticles are iron oxide $\left(\mathrm{Fe}_{3} \mathrm{O}_{4}\right)$ in the form of maghemite or magnetite. They become super paramagnetic at a size less than $128 \mathrm{~nm}$. These NPs become magnetic only when an external magnetic field is applied. The surface of magnetite NPs is relatively inert and does not allow functionalization by covalent bond formation. However, the reactivity can be improved by coating with a layer of silica [35]. The silica shell can then be modified via covalent bond formation of the surface silanol groups with various functionalizing molecules or fluorescent dyes (Figure 2).
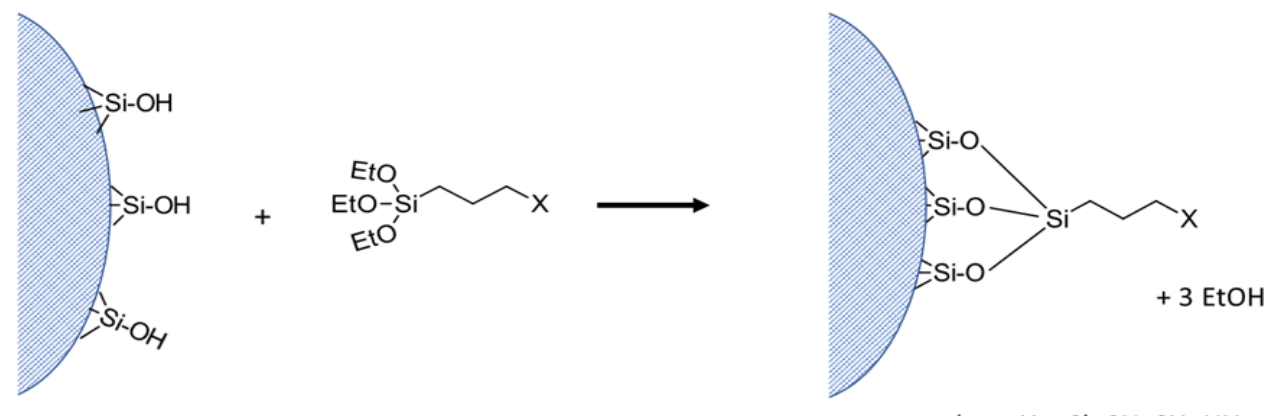

where $\mathrm{X}=\mathrm{Cl}, \mathrm{CN}, \mathrm{SH}, \mathrm{NH}_{2}, \mathrm{C}_{\mathrm{n}}$ etc.

Figure 2: Surface functionalization of magnetic NPs via silica coating and silanization

These particles have several advantages compared to metallic nanoparticles: higher chemical stability, higher colloidal stability (do not agglomerate) and the magnetic moment can be tuned by varying the size [36-40]. It is of great importance that the NPs are biocompatible. Therefore, coating of NPs is one of the most exploited strategies to prevent toxic side effects. In addition to the biocompatibility, coating could modify the pharmacokinetics and bio-distribution of iron oxide NPs. For example, it was shown that iron oxide NPs coated with polyethylene glycol had a residence time twice that of uncoated particles and reduced accumulation in the liver and spleen [41]. Coating of iron oxide nanoparticles with dextran permits conjugation with a variety of functional groups that also facilitate imaging by MRI and other combined modalities such as MRI/PET/CT/fluorescence [42].

In addition to magnetic iron oxide, a variety of other metal oxides such as cobalt, manganese, and nickel have been investigated for biomedical applications because of their intrinsic imaging properties for MRI T2 contrast [29, 43-46]. Engineered magnetic nanoparticles can serve as nanotheranostics because they can be noninvasively imaged by MRI, and with appropriate nanoformulation can also serve as platforms for drug delivery and hyperthermia [47-48]. Yellappu MM et al. have reported the preparation of waterdispersible betacyclodextrin-pluronic F127-coated iron oxide nanoparticles that exhibited hyperthermia properties under an alternating magnetic field. This formulation had improved MRI characteristics when tested on cisplatin-resistant ovarian cancer cells and the curcuminloaded system exhibited inhibition of ovarian, breast and prostate cancer cells [49]. These authors have also tested PEG- functionalized magnetic nanoparticles as a drug delivery system for magnetic resonance imaging and for their ability to conjugate to an antibody. They have prepared a water dispersible iron oxide core coated with oleic acid and PEG. Doxorubicin was then incorporated in to the oleic acid layer. MRI contrast properties were determined in-vitro and the circulation of MNPs measured in mouse carotid arteries. The system was further conjugated with aminogroup of antibodies via the $\mathrm{N}$-hydroxysuccinimide pathway and used for targeting to human breast cancer cell line (MCF-7). The optimized formulation had a hydrodynamic diameter of $184 \mathrm{~nm}$ and the iron oxide core had a diameter of $8 \mathrm{~nm}$. The MNPs enhanced the T2 MRI contrast and showed sustained drug release [50]. Multifunctional pH-sensitive polymeric nanoparticle system for simultaneous tumor magnetic resonance imaging and therapy was developed by Liu et al. The nanoparticles were selfassembled using the multi block polymer, poly (lactic acid) - poly (ethylene glycol) - poly (L-lysine) - diethylenetriaminepenta acetic acid and the $\mathrm{pH}$-sensitive material poly (L-histidine) poly (ethyleneglycol) biotin. The drug sorafenib (anti-hepatocellular carcinoma drug) was encapsulated in the nanoparticles. Another pH-sensitive platform was prepared from Gadolinium DTPA complex and vascular endothelial growth factor receptor (VEGFR)-linked to surface biotin group. This system was shown to have higher antitumor effects compared to free sorafenib in VEGFR over-expressed cell line in mice and high MRI resolution [51].

Another development in this area is the "NanoTherm 
therapy" introduced by MagForce, Germany and approved by European Medicine Agency in 2013 for glioblastomas (the most frequent and malignant brain tumors). This therapeutic option is now available in 27 countries in Europe. The main components of the system are: aminosilane-coated superparamagnetic iron oxide nanoparticles (12-15 $\mathrm{nm}$ diameters), simulation software (NanoPlan), an alternating magnetic field device (NanoActivator) and a catheter for insertion (thermometry probe). Following an injection of the nanoparticles into the tumor, they are exposed to an external alternating magnetic field to generate heat within the tumor. Hyperthermia and thermal ablation of the tumor follows [52].

\section{Nanoparticles used in cancer nanotheranostics}

\section{Liposomes}

Liposomes are small bilayer vesicles made up of phospholipids and cholesterol. They are spherical and the size is generally less than $400 \mathrm{~nm}$. Liposomes are useful platforms for a drug/diagnostic agent's delivery owing to their size, hydrophobic and hydrophilic character, biocompatibility, biodegradability, low toxicity and immunogenicity. The nanosized diagnostic agents such as iron oxide nanoparticles, quantum dots and gold nanoparticles can be entrapped within the theranostic liposomes and the therapeutic agent can be either encapsulated in the inner aqueous core or embedded in the outer lipophilic bilayer shell [58-63].

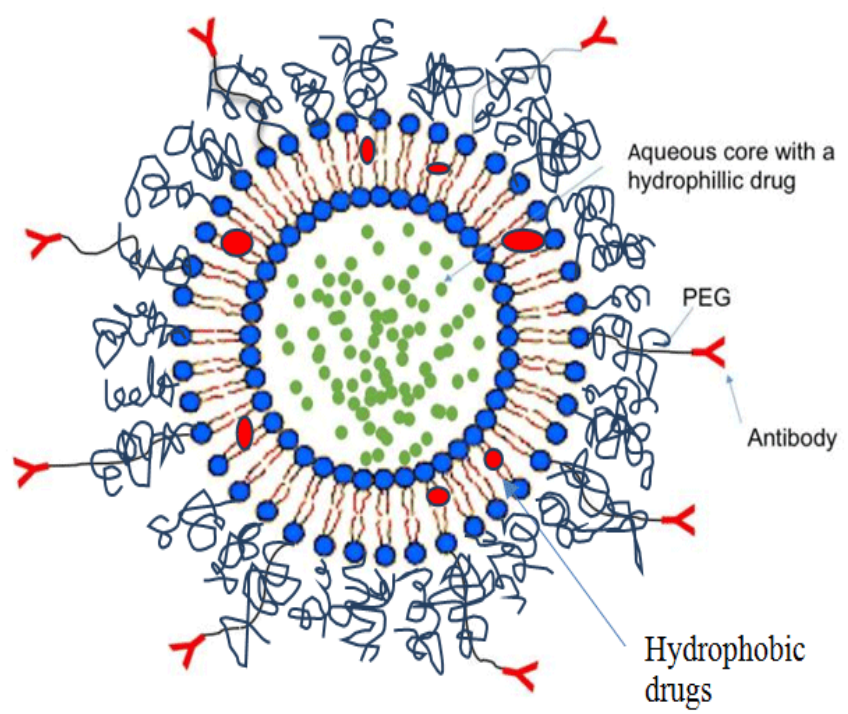

Figure 3: Antibody-attached liposomes for selective targeting to tumors

Advanced theranostic liposomes can be conjugated with molecular biomarkers for their targeting effect. To overcome opsonization by the immune system and fast elimination from blood circulation, stealth liposomes (e.g. PEG-coated liposomes), were formulated to have more stability and a longer half-life in blood. Diagnosis by theranostic liposomes is done with magnetic resonance (MRI), positron emission tomography (PET), single photon emission computed tomography (SPECT) and near infrared (NIR) fluorescence imaging. An imaging agent, a therapeutic agent and a molecular probe can be entrapped in the liposome. 


\section{Micelles}

Micelles are emerging as multifunctional nanothrerapeutic platforms for cancer imaging and delivery of chemotherapeutics. Micelles are self-assembling colloidal structures with a hydrophobic core and hydrophilic shell. (Figure 4). They have a narrow size distribution and a size of less than $100 \mathrm{~nm}$ [64-66].

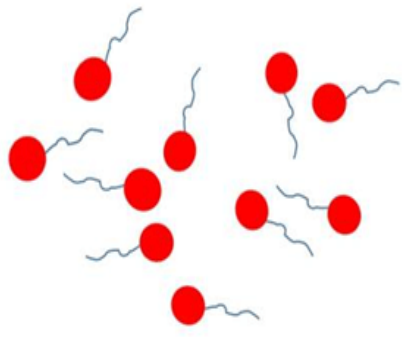

Surfactant monomers

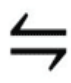

Figure 4: Formation of polymeric micelles from monomers

The inner hydrophobic core of the micelle is loaded with therapeutic/diagnostic and a targeting agent is placed in the outer hydrophilic layer [67-70]. Another example is a multifunctional micellar platform for delivery of doxorubicin and an MRI agent. The micelles were prepared from polyethylene glycol-polylactic acid (PEG-PLA). Super paramagnetic iron oxide (SPION 8nm dia.) was loaded in to the core of the micelles and RGD peptide was conjugated on the micelle ( $45-48 \mathrm{~nm}$ ) for selective targeting to integrin over expressed on endothelial tumor cells [71].

\section{Dendrimers}

From the Greek, dendron means "tree" and meros means "part". They consist of a central core molecule from which a number of highly branched tree-like arms originate in an ordered symmetrical fashion. They have three components: a central core, branches and terminal functional groups. Monomers attached to the core are called first generation. Two monomers are then added to the first generation to give a secondgeneration dendrimer. Molecular weight nearly doubles with each generation. As the number of generations increase, the molecule becomes more and more spherical and too tight for further addition. The interior hydrophobic space can be used for encapsulating drugs or imaging agents or the terminal groups can be attached to drugs for targeted delivery (Figure 5). In addition, dendrimers can be designed for specific applications and functionalities added for bioconjugation. Their size is close to DNA, insulin, cytochrome and hemoglobin. Other advantages of dendrimers include absence of immunogenicity and the possibility of preparing $\mathrm{pH}$-sensitive and temperature sensitive delivery devices.

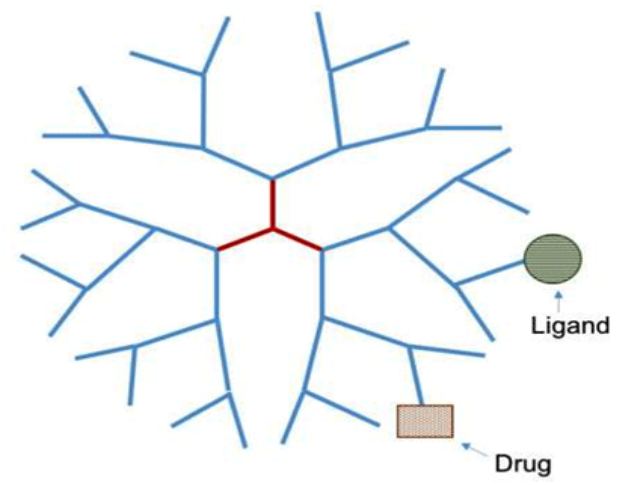

\section{人 Core unit Branching}

\section{Dendrimers}

Figure 5: Multifunctional Dendrimers

Dendrimers have several unique physicochemical properties that make them attractive for biomedical applications.Dendrimers used in nanotheranostics are usually 10 to $100 \mathrm{~nm}$ [72]. By controlling the degree of polymerization, dendrimers can be synthesized in various sizes, molecular weights and chemical compositions [73-74]. 
Solid lipid nanoparticles (SLNPs): SLNPs are made up of a solid hydrophobic core containing dissolved or dispersed drug. They are nanomedicines made from biocompatible lipids (e.g., triglycerides) which are solid at room temperature. The size of less than $100 \mathrm{~nm}$ allows SLNPs to cross tight-endothelial cells of blood-brain barrier for brain targeting. Like other nanomedicines, SLNPs are used for targeted co-delivery of diagnostic and therapeutic agents as theranostic platform [75-76].

\section{Drug-polymer conjugates}

Drug-polymer conjugates consist of a drug and polymer held together by covalent interaction. They are prepared by chemical reactions that mostly depend on the functional groups present in the drug and polymeric carrier. The two major types of conjugates include protein conjugates and drug conjugates with appropriate polymers [77]. The most successful polymer for theranostic drug-polymer conjugates is $\mathrm{N}$-(2hydroxy propyl) methacrylamide (HPMA). HPMA-based conjugates are used for theranostics since they are stable, non-toxic and biocompatible for in vivo applications [78-79]. Targeted NPs are constructed by incorporating a variety of ligands including transferrin, lactoferrin, aptamers and numerous peptides. The use of reactive groups (including carboxylic acids, amines, thiols and succinimide derivatives) allows for the direct chemical bonding of the targeting ligand to the nanoparticle (Figure 6).

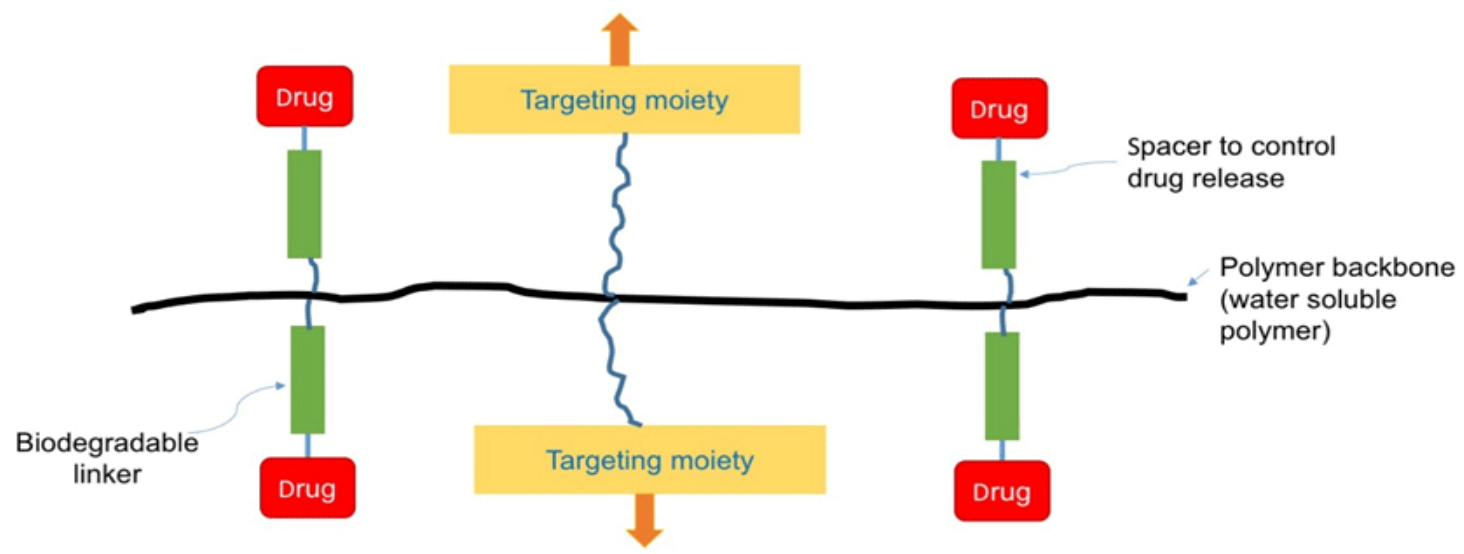

Figure 6: Drug-polymer conjugate for targeted delivery

\section{Carbon nanotubes (CNT)-based theranostics}

Carbon nanomaterials are useful nano platforms for cancer theranostics because of their physicochemical and mechanical properties. Photothermal ablation of tumors is possible because of the inherent near infrared optical absorbance. This absorption property also leads to their visualization by nearinfrared photoluminescence. Another advantage of carbon nanotubes is their high surface area and high aspect ratio (obtainable with various shapes). This facilitates attachment of theranostic moieties, imaging labels (radioisotopes, fluorescent dyes) targeting ligands (antibodies, peptides), therapeutics (drugs, genes) as well as polymers to achieve enhanced water solubility and stability [80].

CNTs are synthesized by several techniques including high pressure carbon monoxide, chemical vapor deposition and arc discharge methods [81]. In single walled carbon nanotubes (SWCNTs), carbon atoms are exposed on the surface, resulting in very high surface area $\left(1300 \mathrm{~m}^{2} / \mathrm{g}\right)$. When these SWCNTs are exposed to laser light, the local heating produced leads to emission of ultrasound waves (due to the photoacoustic effect). Thus SWCNTs have unique properties which make them suitable for applications in a variety of imaging modalities such as magnetic resonance, near infrared fluorescence, Raman spectroscopy, and photoacoustic tomography [82]. Raman scattering of SWCNTs has been explored for in-vitro and in-vivo imaging of biological samples. The strong absorbance in the near IR region can be used for photoacoustic imaging, which is further enhanced by coating with gold shells.

CNTs are amenable to surface functionalization. Functionalization is important, not only to increase target specificity but also to increase aqueous solubility and stability. It is also known that the functionalized CNTs have lower cytotoxicity compared to their non-functionalized counterparts. Covalent and non-covalent surface functionalization of CNTs has been reported in the literature. A disadvantage of covalent bonds is their interference with the natural physical properties (e.g. Raman scattering and photoluminescence) of CNTs, which is not apparent with non-covalent functionalization. In noncovalent functionalization, the surface of the CNT is coated with amphiphilic surfactant molecules or polymers. Thus, the hydrophobic surface of the NT is non-covalently attached to the hydrophobic tail of the surfactant. SWCNTs have also been radiolabeled with $64 \mathrm{Cu}$ (for imaging tumor angiogenesis). The CNT-based contrasts agents facilitated minimally invasive, 
highly sensitive and target-specific detection and killing of solid and metastatic tumor cells. These functionalized carbon nanotubes with radioactive isotopes are used for nuclearimaging [83]. A theranostic Multiwalled Carbon Nanotube (MWCNT) was designed by Das et al. that included acid-oxidized MWCNT with four varieties of functional moieties: a fluorochrome (Alexa-fluor, AF488/647), targeting agent (i.e, folic acid), radionuclide (Technitium-99m), and methotrexate [87]. The cellular uptake studies showed the selective internalization of theranostic MWCNTs by folate receptor- positive human lung (A549) and breast (MCF-7) cancer cells through folate receptor mediated endocytosis. The tumor-specific accumulation of targeted theranostic MWCNTs in xenografted mice after $24 \mathrm{~h}$ was 19.14 and 8.62 times higher in comparison to free and nontargeted theranostic MWCNTs. This study shows the controlled delivery of methotrexate from theranostic MWCNTs, receptor mediated delivery, optical detectability of fluorochromes, and radio-traceability of $99 \mathrm{mTc}$. In another study, cationic, anionic and non-ionic MWCNTs were prepared by Chen et al. [85]. The surface charge was controlled by varying the grafting reagents and the degree of grafting established by thermal analysis and high-resolution transmission electron microscope. The CNTs had improved solubility and stability in water and cell culture medium.

\section{Peptide based targeting strategies}

Peptide-based, drug-encapsulated nanovectors (liposomes, micelles) represent a new frontier in cancer therapy. They can be used to selectively carry a drug to target cells while incorporating an imaging probe to guide or monitor therapy [86]. A number of molecular targets for peptides are exclusively expressed or overexpressed on both cancer vasculature and cancer cells. For example, the integrins, growth factor receptors and G-protein coupled receptors. Peptides have some advantages as targeting molecules compared to the monoclonal antibodies: rapid blood clearance, ready penetration into vascular endothelium, increased diffusion rate into tissues and low immunogenicity [87]. In addition, receptor-targeted peptides are internalized within tumor cells by receptormediated endocytosis. In one example, the gastrin-releasing protein receptor was targeted with gold nanorods conjugated to a synthetic bombesin. This may provide an opportunity for developing a system for in-vivo molecular imaging and therapy [88]. The integrin based targeting strategies were used by Zhang et al for RGD peptide-conjugated iron oxide nanoparticles [89] and the integrin-targeted liposomal doxorubicin-RGD peptide for imaging and treating metastatic disease [90]. This peptide sequence selectively recognized the $\alpha \mathrm{V} \beta 3$ integrin receptor expressed on angiogenic endothelium. Doxorubicin was encapsulated by the remote loading method and the liposomes were made fluorescent with DOPE-BODIPY 630/650. Theranostic liposomal doxorubicin attached to a novel peptide with high affinity to lung tumor was studied by Le et al. for imaging and targeted delivery to lung tumor [91].

\section{Hyperthermia: Converting optical energy in to heat}

Hyperthermia is known to induce apoptotic cell death in cancer tissues and increase survival of the cancer patient when combined with radiotherapy and chemotherapy. Hyperthermia has been delivered by radiofrequency waves, microwaves or ultrasound. However, a limitation is the difficulty in heating deepseated tumors to effective temperatures. It is well known that different nanomaterials such as gold, magnetic NPs and carbonbased NPs can convert optical energy into heat by electron excitation and relaxation. Furthermore, infrared lasers can be tuned to the specific plasmon resonance of the nanoparticles [48, 92]. Additionally, multifunctional nanoplatforms are fabricated for simultaneous imaging, treatment monitoring and release of therapeutics with hyperthermia treatment (photothermal therapy, PTT). For example, a composite of reduced graphene oxide and iron oxide nanoparticles functionalized with PEG was developed for image-guided therapy [93]. This combination allowed for strong NIR optical absorbance, superparamagnetic properties, and physiological stability for in vivo applications. The composite was imaged by fluorescence, photoacoustic and MR imaging, and used for photothermal ablation of tumors in mice using 808-nm NIR laser. A major advantage of this nanotheranostic probe is treatment monitoring by MRI. After therapy, T2-weighted MRIs were acquired to monitor the tumor size because of the pooling of the nanocomposite imaging agent [93]. In a more recent study, graphene oxideBaGdF5 nanocomposite was used for multimodal imaging (MRI and X-ray computed tomography) and photothermal ablation of tumors in vivo [94]. In another study, quantum dots were prepared with reduced graphene oxide-iron oxide and used for photothermal ablation of HeLa cell in-vitro. The QDs emitted violet light when excited at $320 \mathrm{~nm}$. The suitability of the QDs for fluorescent and magnetic resonance dual-modality imaging was shown by in-vitro imaging with dermal fibroblast cells and T2 relaxation time [95]. This report also showed the loading of a drug (lidocaine hydrochloride) on to surface of the QDs and targeted delivery employing an external magnet.

\section{Photodynamic therapy (PDT)}

Photodynamic therapy (PDT) is based on the formation of lethal singlet oxygen as well as emission of fluorescence when a photosensitizer such as photofrin (Porfimer sodium, approved by FDA) and phthalocyanine are irradiated with a laser of specific wavelength following their targeted delivery to a tumor. Porphyrins and phthalocyanines, which share an aromatic and planar tetrapyrrole backbone, are ideally suited for intrinsic multifunctional imaging and therapeutic applications [96].

Photosensitizers are highly colored naturally occurring materials which undergo photochemical reaction to generate reactive oxygen species (ROS) that can cause tumor cell death. ROS have a very short half-life and therefore act only at the site of their generation. Photosensitizers are harmless in the absence of light and oxygen. These agents can be concentrated in the tumor tissue by delivering them in some form of nanoparticle delivery system. This can permit simultaneous therapy and imaging [97-98]. Cheng et al. utilized metallic NPs to deliver the PDT drug phthalocyanine to brain tumors 
while monitoring drug uptake by fluorescence methods [99]. One of the limitations of fluorescence imaging is the limited tissue penetration of visible light required for activation of the photosensitizer. This limitation may not be serious for imaging flat lesions but presents problems for imaging tumors at greater depths. This may be overcome by using multimodal techniques that can complement fluorescence such as PET, MRI and multiphoton excitation $[100,101]$. The phthalocyanins are activated by light in the near infrared region of 700-900 nm, also known as the NIR optical window. Body tissues are transparent in this region of the spectra. Therefore, photosensitizers in deep seated cancer tumors can be activated (Figure 7) [97].

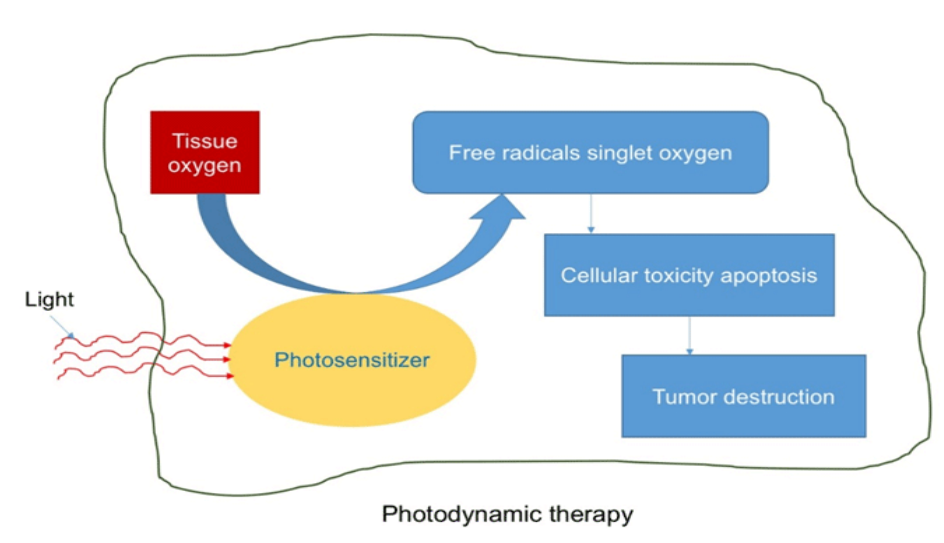

Figure 7: Photodynamic therapy

One drawback of the phthalocyanines is their poor aqueous solubility. Strategies to enhance water solubility include encapsulation in micelles, liposomes and nanoparticles, as well as chemical conjugation with hydrophilic polymers and tumortargeted moieties [102-107].

Dendrimers also have been evaluated for tumor-targeted delivery of phthalocyanins. Dendrimers have the advantage of high water solubility and high encapsulation efficiency for hydrophobic drugs [108].

\section{Quantum dot-based theranostics}

Quantum dots (QDs) are semiconductor nanocrystals that emit fluorescence on excitation with a light source. They have excellent optical properties, including high brightness, resistance to photobleaching, and tunable wavelength.
Recent developments in surface modification of QDs enable their potential application in cancer imaging. QDs with nearinfrared emission could be applied to sentinel lymph-node mapping to aid biopsy and surgery. Conjugation of QDs with biomolecules, including peptides and antibodies, could be used to target tumors in vivo. These engineered fluorescent probes with integrated imaging and carrier functionalities have become excellent tools for molecular diagnostics and delivery of therapeutic molecules. Flexible surface chemistry, unique optical properties, high sensitivity, and multiplexing capabilities of QDs certainly make them a most promising tool for personalized medicine.

The tiny QDs have sizes ranging from 3 to $10 \mathrm{~nm}$. They can be made to emit wavelengths ranging from 450 to $1600 \mathrm{~nm}$ by changing their size, shape, and composition.

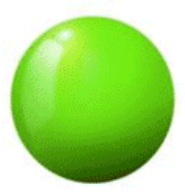

$535 \mathrm{~nm}$

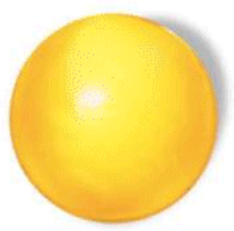

$560 \mathrm{~nm}$

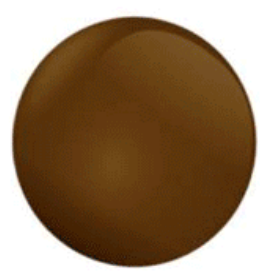

$585 \mathrm{~nm}$

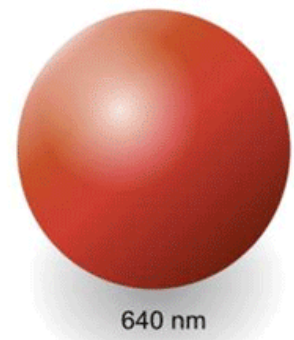

$640 \mathrm{~nm}$

\section{CdSe quantum dots}

Figure 8: Dependence of color on size of quantum dots 
Due to their unique tunable spectral and optoelectronic properties, QDs have been extensively employed for various biomedical and medicinal research applications [109-112]. The surface of quantum dots can be functionalized with biomolecules to selectively target specific sites in-vitro and invivo. For example, bioconjugated quantum dots have been used in targeted cell labeling, tissue imaging, photodynamic therapy, in-vivo tumor detection, and drug delivery (Figure 9) [113-115].

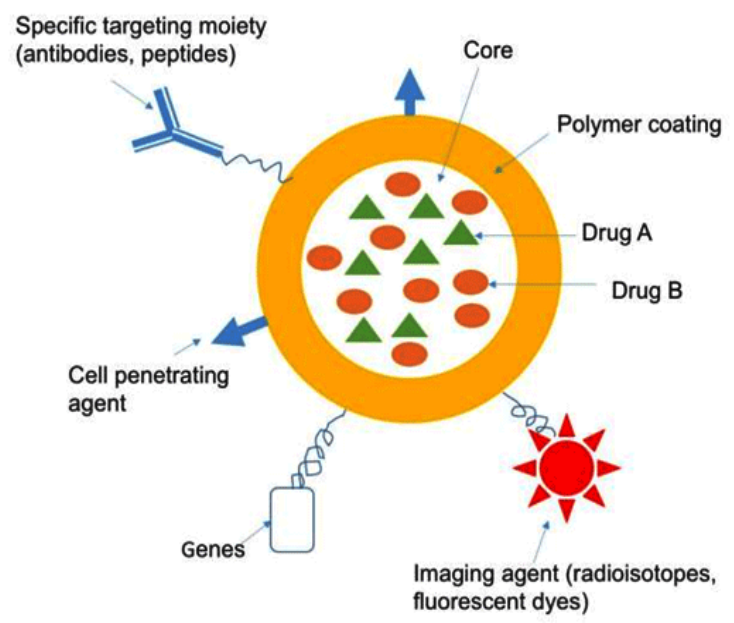

Figure 9: Multifunctional QDs

The imaging property of quantum dots can also be utilized by encapsulating them in other nanocarriers such as micelles and liposomes. For example, bioconjugated pluronic triblock copolymer micelle-encapsulated QDs were used for targeted cancer imaging. In this study, the authors showed that folic acid can be conjugated to QDs for the targeted delivery to the tumor site by exploiting over-expressed folic acid receptors on the tumor cells $[67,68]$. Another advantage of encapsulating QDs in pegylated phospholipid micelles is the reduced toxicity of QDs (as in the case of PbS), and their near infra-red absorption for in-vitro and in-vivo imaging studies [116]. It was also shown that quantum dots could be encapsulated within liposomes that contain cisplatin, for drug delivery and imaging. In this study, the authors observed the fluorescence signal and cisplatin accumulation in the brain and skin melanoma cells [117]. While theranostic QDs have demonstrated potential in proofof-concept applications using cultured cells and small animal models, concern surrounding the toxicity of the semiconductor core has prevented their clinical translation. Use of heavy metal based quantum dots as theranostic probes in humans is a major concern. In future, biocompatible, non-immunogenic, ultra-small size $(<5.0 \mathrm{~nm})$ quantum dots for nanomedicine will probably be introduced [118-120].

\section{Conclusions}

Theranostic nanoparticles are being developed as vehicles for the simultaneous delivery of both imaging agents and drugs. The unique properties of nanomaterials, such as their ability to be concentrated in tumor tissue by passive or active targeting and their optical/magnetic properties for imaging by MRI/CT/fluorescence are exploited in the fabrication of theranostic nanoplatforms. Magnetic resonance imaging (MRI) is perhaps the most efficient tool for diagnosis, the efficiency of which is further enhanced by a magnetic nanoparticle. MRI provides invaluable anatomical details, while processes such as metabolism, enzyme activity, oxygen metabolism and blood flow can be characterized by positron emission tomography. These nanoplatforms serve multiple functions simultaneously such as drug and imaging agent delivery, targeting to desired site and controlled release. Real time visualization of cancer cells and drug release pattern is useful in optimizing the dose and treatment schedule. Monitoring of therapeutic response helps in assessing efficacy of treatment as well as in modifying treatment strategies. All these aspects may ultimately lead to personalized care of the cancer patient. Theranostics eliminate the trial-and-error medicine to more precise personalized medicine and hold great promise for improved patient outcome. In addition, the precise targeting property of the theranostic device can help to improve the safety profile of a drug as well as minimizing off-target effects often seen with cancer chemotherapeutic agents. Advances in new imaging techniques and novel types of molecular probes have made it possible for more accurate tumor detection, cancer staging, and real-time monitoring of cancer progression and therapeutic outcomes. 


\begin{tabular}{|c|c|c|c|c|c|}
\hline $\begin{array}{l}\text { Type of nano- } \\
\text { Theranostic } \\
\text { nanomedicine }\end{array}$ & Material & $\begin{array}{c}\text { Therapeutic } \\
\text { agent }\end{array}$ & $\begin{array}{l}\text { Diagnostic } \\
\text { agent }\end{array}$ & $\begin{array}{c}\text { Targeting } \\
\text { agent }\end{array}$ & Properties/advantages \\
\hline Gold & $\begin{array}{c}\text { Gold NPs } \\
\text { functionalized with } \\
\text { Doxorubicin and } \\
\text { peptide }\end{array}$ & DOX & Gold & peptide & $\begin{array}{c}\text { Cell-penetrating } \\
\text { peptidemodified } \\
\text { AuNPs for delivery of } \\
\text { Doxorubicin to brain } \\
\text { metastatic breast cancer. }\end{array}$ \\
\hline Gold & $\begin{array}{l}\text { TNF- } \alpha \text { conjugated- } \\
\text { to thiol- } \\
\text { derivatized- } \\
\text { PEG gold-NP } \\
\text { (CYT 6091) }\end{array}$ & TNF- $\alpha$ & Gold & TNF- $\alpha$ & $\begin{array}{c}\text { Now in phase } 2 \text { trials in humans. } \\
\text { TNF- } \alpha \text { preferentially accumulate } \\
\text { in } \\
\text { tumor. TNF- } \alpha \text { has potent } \\
\text { anticancer } \\
\text { activity but direct use results in } \\
\text { Systemic toxicity. It is also used } \\
\text { for } \\
\text { radiofrequency ablation of } \\
\text { tumors }\end{array}$ \\
\hline Gold & $\begin{array}{l}\text { Gold NPs } \\
\text { functionalized with } \\
\text { paclitaxel and biotin }\end{array}$ & Paclitaxel & gold & biotin & $\begin{array}{l}\text { Biotin-mediated cancer } \\
\text { theranostic } \\
\text { agent. Biotin demand in the } \\
\text { rapidly } \\
\text { growing tumors is higher than in } \\
\text { normal tissues. }\end{array}$ \\
\hline Carbon nanotubes & SWCNTS & $\begin{array}{l}\text { Intrinsic } \\
\text { property }\end{array}$ & $\begin{array}{c}\text { Intrinsic } \\
\text { Property/radio } \\
\text { Isotopes, }\end{array}$ & $\begin{array}{l}\text { Passive or } \\
\text { antibodies }\end{array}$ & $\begin{array}{c}\text { Radioisotopes, antibodies can be } \\
\text { Attached for MRI, NIR } \\
\text { fluorescence, } \\
\text { Raman spectroscopy, } \\
\text { photoacoustic } \\
\text { tomography }\end{array}$ \\
\hline $\begin{array}{l}\text { Magnetic NPs } \\
\text { "Nanotherm" } \\
\text { therapy }\end{array}$ & $\begin{array}{l}\text { Super paramagnetic- } \\
\text { iron oxide, } \\
\text { alternating magnetic- } \\
\text { field }\end{array}$ & Heat & Iron oxide & passive & $\begin{array}{l}\text { For imaging glioblastoma. NPs in } \\
\text { tumor is exposed to alternating } \\
\text { magnetic field to generate heat } \\
\text { within the tumor for } \\
\text { thermal ablation. }\end{array}$ \\
\hline Magnetic NPs & $\begin{array}{l}\text { Manganese-doped } \\
\text { Magnetic iron oxide, } \\
\text { Contains siRNA and } \\
\text { RGD }\end{array}$ & siRNA & Iron oxide & RGD & $\begin{array}{l}\text { Target integrin over-expressed } \\
\text { in } \\
\text { metastatic tumor cells. Uptake of } \\
\text { the gene is imaged by MRI due } \\
\text { to T2 } \\
\text { contrast provided by manganese } \\
\text { and by } \\
\text { fluorescence dye labelled on } \\
\text { siRNA. }\end{array}$ \\
\hline
\end{tabular}




\begin{tabular}{|c|c|c|c|c|c|}
\hline Liposomes & $\begin{array}{l}\text { Phospho- } \\
\text { Lipids, cholesterol, } \\
\text { Pegylated Vitamin E }\end{array}$ & Docetaxel & $\begin{array}{l}\text { Quantum } \\
\text { dots }\end{array}$ & Folic acid & $\begin{array}{l}\text { Pegylated vitamin is a good } \\
\text { emulsifier, Increases water } \\
\text { solubility of anticancer } \\
\text { agents and bioavailability. } \\
\text { Co-delivery of docetaxel and } \\
\text { QDs. }\end{array}$ \\
\hline Liposomes & $\begin{array}{l}\text { Phospholipids } \\
\text { Cholesterol, apo- } \\
\text { morphine }\end{array}$ & Apomorphine & Quantum dots & passive & $\begin{array}{l}\text { Brain-targeted apomorphine. } \\
\text { Fluorescence derived from } \\
\text { quantum dots for bioimaging }\end{array}$ \\
\hline Dendrimers & $\begin{array}{l}\text { Polypropyline- } \\
\text { imine }\end{array}$ & Phthalocyanines & Phthalocyanines & LHRH & $\begin{array}{l}\text { For photodynamic therapy and } \\
\text { Intrinsic fluorescent property } \\
\text { of phthalocyanines for } \\
\text { fluorescence } \\
\text { Imaging }\end{array}$ \\
\hline Polymeric NPs & PLA-TGPS & Docetaxel & $\begin{array}{l}\text { Quantum } \\
\text { dots }\end{array}$ & Folic acid & $\begin{array}{l}\text { Co-delivery of docetaxel and } \\
\text { QDs. }\end{array}$ \\
\hline $\begin{array}{l}\text { Drug-polymer } \\
\text { conjugate }\end{array}$ & HPMA & ${ }^{64} \mathrm{Cu}$ & ${ }^{64} \mathrm{Cu}$ & RGD & $\begin{array}{l}\text { Stable, non-toxic, biocompatible. } \\
\text { Cancer imaging and radio } \\
\text { Chemotherapy. Positron } \\
\text { emission } \\
\text { Tomography for tumor } \\
\text { localization. } \\
\text { Targeting tumor angiogenesis. } \\
\text { Transferrin, lactoferrin and } \\
\text { peptides } \\
\text { can be attached. }\end{array}$ \\
\hline $\begin{array}{l}\text { Drug polymer } \\
\text { conjugate }\end{array}$ & HPMA & Doxorubicin & Iodine-131 & passive & $\begin{array}{l}\text { Studied in phase } 1 \text { clinical trial. } \\
\text { Indium } 111 \text { as diagnostic agent } \\
\text { and } \\
\text { RGD as targeting agent also have } \\
\text { been studied. }\end{array}$ \\
\hline \multicolumn{6}{|c|}{$\begin{array}{l}\text { Abbreviations: SWCNTs= single-walled carbon nanotubes; TPGS= } \sigma \text {-Tocopheryl polyethylene glycol } 1000 \text { succinate } \\
\text { PLA= poly-lactic acid; HPMA = N-(2-hydroxypropyl) methacrylamide; DOX= Doxorubicine } \\
\text { RGD= Arg-Gly-Asp }\end{array}$} \\
\hline
\end{tabular}

\section{References}

1. Kaul G, Amiji M. Long-circulating polyethylene glycol-modified gelatin nanocapsules for intracellular delivery. Pharm Res 2002;19(7):1061-1067.

2. Cai W, Chen X. Nanoplatforms for targeted molecular imaging in living subjects. Cai, W, Chen X. Small. 2007;3(11): 1840-1854. DOI: 10.1002/smll.200700351

3. Janib SM, Moses AS, MacKay JA. Imaging and drug delivery using theranostic nanoparticles. Adv Drug Deliv Rev. 2010;62(11):10521063. DOI: $10.1016 /$ j.addr.2010.08.004

4. Kelkar SS, Reineke TM. Theranostics: combining imaging and therapy. Bioconjug. Chem. 2011;22(10):1879-1903. DOI: 10.1021/ bc200151q

5. Xie J, Lee S, Chen X. Nanoparticle-based theranostic agents.
Adv Drug Deliv Rev. 2010;62(11):1064-1079. DOI: 10.1016/j. addr.2010.07.009

6. Yu MK, Park J, Jon S. Targeting strategies for multifunctional nanoparticles in cancer imaging and therapy. Theranostics. 2012;2(1):3-44. DOI: 10.7150/thno.3463

7. Farokhzad OC, Langer R. Nanomedicine: developing smarter therapeutic and diagnostic modalities. Adv Drug Deliv Rev. 2006;58(14):1456-1459. DOI: 10.1016/j.addr.2006.09.011

8. Swierczewska M, Lee S, Chen X. Moving theranostics from bench to bedside in an interdisciplinary research team. Ther Deliv. 2011;2(2):165-170.

9. Kateb B, Chiu K, Black KL,Yammamoto V, Khalsa BL Iubemova JY, et al. Nanoplatforms for constructing new approaches to cancer treatment, imaging and drug delivery: what should be 
the policy. NeuroImage 2011;54(suppl):s106-S124 doi: 10.1016/ jneuroimage.2010.01.105.

10. Yang L, Mao H, Cao Z, Wang YA, Peng X, Wang X, et al. Molecular imaging of pancreatic cancer in animal model using targeted multifunctional nanoparticles. Gastroenterology. 2009;136(5):1514-1525. DOI: 10.1053/j.gastro.2009.01.006

11. Conde J, Dias JT, Grazu V, Moros M, Baptista PV, de la Fuente JM. Revisiting 30 years of biofunctionalization and surface chemistry of inorganic nanoparticles for nanomedicine. Front Chem. 2014;2:48. DOI:10.3389/fchem.2014.00048.

12. Hyeon T. Chemical synthesis of magnetic nanoparticles. Chem. Commun. 2003;21(8):927-934.

13. Laurent S, Forge D, Port M, Roch A, Robic C, Elst LV, et al. Magnetic iron oxide nanoparticles: synthesis, stabilization, vectorization, physicochemical characterizations, and biological applications. Chem. Rev. 2008;108(6): 2064-2110.

14. Gao H1, Qian J, Cao S, Yang Z, Pang Z, Pan S, et al. Precise glioma targeting of and penetration by aptamer and peptide dualfunctioned nanoparticles. Biomaterials. 2012;33:5115-5123. DOI: 10.1016/j.biomaterials.2012.03.058

15. Mejías R1, Pérez-Yagüe $S$, Roca AG, Pérez N, Villanueva A, Cañete $\mathrm{M}$, et al. Liver and brain imaging through dimercaptosuccinic acid-coated iron oxide nanoparticles. Nanomedicine (Lond.)2010;5(3):397-408. DOI: 10.2217/nnm.10.15

16. Lee H, Lee WC. A comparison of co-precipitation with microemulsion methods in the preparation of magnetite. J Appl. Physics. 1999;85(8):5231.

17. Wang B, Wei Q, Qu S. Synthesis and characterization of uniform and crystalline magnetite nanoparticles via oxidation-precipitation and modified co-precipitation methods. Int J Electrochem Sci., 2013;8(3):3786-3793.

18. Ren QQ, Bai LY, Zhang XS, Ma ZY, Liu B, Zhao YD, et al. Preparation, modification and application of hollow gold nanospheres. Journal of nanomaterials. 2015; article ID 534070.

19. Huang C, Jiang J, Muangphat C, Sun, X, Hao Y. Trapping Iron oxide in to Hollow Gold Nanoparticles. Nanoscale Res Lett, 2010;6(1):43. DOI: 10.1007/s11671-010-9792-x.

20. Ratto F, Matteini P, Rossi F, Pini R. Gold nanorods for photothermal therapies. Journal of biophotonics. 2011;4:64-73 doi: 10.1002/ jbio. 201000002.

21. Alex S, Tiwari A. Functionalized gold nanoparticles: properties and applications- a review. Journal of nanoscience and nanotechnology. 2015;15(3):1869-1894.

22. Nicol JR, Dixon D, Coulter JA. 2015 Gold nanoparticle surface functionalization: a necessary requirement in the development of novel nanotherapeutics. Nanomedicine. 2015;10(8):1315-1326. DOI: $10.2217 / \mathrm{nnm} .14 .219$

23. Akhter S, Ahmad MZ, Ahmad FJ, Storm G, Kok RJ. Gold nanoparticles in theranostic oncology: current state-of-theart. Expert Opin Drug Deliv. 2012;9(10):1225-1243. DOI: $10.1517 / 17425247.2012 .716824$

24. Heo DN, Yang DH, Moon HJ, Lee JB, Bae MS, Lee SC, et al.
Gold nanoparticles surface-functionalized with paclitaxel drug and biotin receptor as theranostic agents for cancer therapy. Biomaterials 2012;33(3):856-866. DOI: $10.1016 / \mathrm{j}$. biomaterials.2011.09.064

25. Shao J, Griffin RJ, Galanzha E, Kim J, Koonce N, Webber J, et al. Photothermal nanodrugs potential of TNF - gold nanospheres for cancer theranostics. Nature (scientific reports). 2013;3:1293. DOI: 10.1038/srep 01293

26. Park JY, Baek MJ Choi ES, Woo S, Kim JH, Kim TJ, et al. paramagnetic ultra-small gadolinium oxide nanoparticles as advanced T1 MRI contrast agent: account for large longitudinal relaxivity, optimal particle diameter and in vivo T1 MR Images. ACS Nano. 2009;3(11): 3663-3669.

27. Mornet S, Vasseur S, Grasset F, Duguet E. Magnetic nanoparticle design for medical diagnosis and therapy. J Mater Chem. 2004;14(14):2161-2175.

28. Na HB, Song IC, Hyeon T. Inorganic nanoparticles for MRI contrast agents. Advanced materials 2009;21:2133-2148 DOI:10.1002/ adma.200802366.

29. Xie J, Jon S. Magnetic nanoparticle-based theranostics. Theranostics. 2012;2(1):122-124. DOI:10.7150/ thno.4051

30. Kim D, Jeong YY, Jon S. A drug-loaded aptamer-gold nanoparticle bioconjugated for combined CT imaging and therapy of prostate cancer. ACS Nano 2010;4(7):3689-3696, doi: 10.1021/nn901877h.

31. Agarwal A, Huang SW, O’Donnel M, Day KC, Day M, Kotoi N et al. Targeted gold nanorod contrast agent for prostate cancer detection by photoacoustic imaging. J Appl Phys 2007;102(64)701704.

32. Cabral RM, Baptista PV. The chemistry and biology of gold nanoparticle-mediated photothermal therapy: promises and challenges. Nano LIFE. 2013;3(3),1330001.

33. Chamberland DL, Agarwal A, Kotoy N, Fowlkes KB, Carson $\mathrm{PL}$, Wang X. Photoacoustic tomography of joints aided by an itanercept-conjugated gold nanoparticle contrast agent-an exvivo preliminary rat study. Nanotechnology 2008,19(9):095101. DOI: 10.1088/0957-4484/19/9/095101

34. Kim K, Huang SW, Ashkenazi S, O’Donnel M, Agarwal A, Kotoy NA et al. Photoacoustic imaging of early inflammatory response using gold nanorods. Appl Phys Lett. 2007;90(22):3901-3903.

35. Kralj Slavko, Makovec Darko, Čampelj Stanislav, Drofenik Miha. Producing ultra-thin silica coatings on iron-oxide nanoparticles to improve their surface reactivity. Journal of Magnetism and Magnetic Materials. 2010;322(13):1847-1853. Bibcode: 2010JMMM.322.1847K. doi:10.1016/j.jmmm.2009.12.038.

36. Dilnawaz F, Singh A, Mewar S, Sharma U, Jagannathan NR, Sahoo SK. The transport of non-surfactant based paclitaxel loaded magnetic nanoparticles across the blood brain barrier in a rat model. Biomaterials 2012;33(10):2936-2951.

37. Hadjipanayis CG, Machaidze R, Kaluzova M, Wang L, Schuette AJ, Chen $\mathrm{H}$, et al. EGFRvIII antibody-conjugated iron oxide nanoparticles for magnetic resonance imaging-guided convection- 
enhanced delivery and targeted therapy of glioblastoma. Cancer Res. 2010;70(15): 6303-6312. DOI: 10.1158/0008-5472.CAN-101022

38. Kievit FM, Veiseh O, Fang C, Bhattarai N, Lee D, Richard G, et al. Chlorotoxin- labeled magnetic nanovectors for targeted gene delivery to glioma. ACS Nano. 2010;4(8):4587-4594. DOI: 10.1021/ nn1008512

39. Liu HL, Hua MY, Yang HW, Huang CY, Chu PC, Wu JS, et al. Magnetic resonance monitoring of focused ultrasound/magnetic nanoparticle targeting delivery of therapeutic agents to the brain. Proc. Natl Acad. Sci. USA 2010;107:15205-15210. DOI: 10.1073/ pnas. 1003388107

40. Veiseh O, Sun C, Gunn J, Kohler N, Gabikian P, Lee D, et al. Optical and MRI multifunctional nanoprobe for targeting gliomas. Nano Lett. 2005;5(6):1003-1008. DOI: 10.1021/nl0502569

41. Ruiz A, Hernandez Y, Cabal C, Gonzalez E, Veintemillas-Verdaguer S, Martinez E. Biodistribution and pharmacokinetics of uniform magnetite nanoparticles chemically modified with polyethylene glycol. Nanoscale. 2013;5:11400-11408. doi: 10.1039/C3NR01412F.

42. Tassa C, Shaw SY, Weissleder R. Dextran-coated iron oxide nanoparticles: a versatile platform for targeted molecular imaging, molecular diagnostics and therapy (review). Accounts of Chemical Research. 2011;44(10):842-852. DOI: 10.1021/ar200084x

43. Hasany S F, Abdurahman NH, Sunarti AR, Jose R. Magnetic iron oxide nanoparticles: Current nanoscience: chemical synthesis and applications review. 2013;9(5):561-575. DOI: 10.2174/15734137113099990085

44. Kievit FM, Zhang M.Surface engineering of iron oxide nanoparticles for targeted cancer therapy. Acc Chem Res. 2011;44(10):853-862 doi: 10.1021/ar2000277

45. Movia D, Poland C, Tran L, Volkov Y, Prina-Mello A. Multilayered Nanoparticles for Personalized Medicine: Translation into Clinical Markets. In: Handbook of Clinical Nanomedicine: Nanoparticles, Imaging, Therapy and Clinical Applications Singapore: Pan Stanford Publishing Ltd. 2016.

46. Yigit MV, Moore A, Medarova Z. Magnetic nanoparticles for cancer diagnosis and therapy. Pharmaceutical research. 2012;29(5):11801188 doi: 10.1007/s11095-012-0679-7

47. Hayashi K, Nakamura M, Sakamoto W, Yogo T, Miki H, Ozaki S, et al. Superparamagnetic nanoparticle clusters for cancer theranostics combining magnetic resonance imaging and hyperthermia treatment. Theranostics. 2013;3(6):366-376. doi: 10.7150/ thno.5860

48. Zhao Q, Wang L, Cheng R, Mao L, Arnold RD, Howerth EW, et al. Magnetic nanoparticle-based hyperthermia for head \& neck cancer in mouse models. Theranostics. 2012;2:113-121 doi:10.7150/thno.3854

49. Yellapu MM, Othman SF, Curtis ET, Gupta BK, Jaggi M, Chauhan SC. Multifunctional magnetic nanoparticles for magnetic resonance imaging and cancer therapy. Biomaterials. 2011;32(7):189018905. doi:10.1016/j.biomaterials.2010.11.028

50. Yellapu MM, Poy SP, Jain TK, Labhasetwar V. PEG-functionalized magnetic nanoparticles for drug delivery and magnetic resonance imaging applications. Pharm Res. 2010;27(11):2283-2295, doi: 10.1007/s11095-010-0260-1

51. Yongjun Liu, LixiaFeng, Tingxian Liu, Li Zhang, Yao Yao, Yu D, et al. Multifunctional PH-sensitive polymeric nanoparticles for theranostics evaluated experimentally in cancer. Nanoscale. 2014;6(6):3231-3242. DOI: 10.1039/c3nr05647c

52. Maier-Hauff K, Ulrich F, Nestler D, Niehoff H, Wust P, Thiesen B et al. Efficacy and safety of intra-tumoral thermotherapy using magnetic iron oxide nanoparticles combined with external beam radiotherapy on patients with recurrent glioblastoma multiforme. J Neuro-oncol. 2011;103(2):317-324. doi: 10.1007/s11060-0100389-0

53. Lee JH, Lee K, Moon SH, Lee Y, Park TG, Cheon J. All-in-one target-cell-specific magnetic nanoparticles for simultaneous molecular imaging and siRNA delivery. Angew Chem Int Ed Engl. 2009;48(23):4174-4179. DOI: 10.1002/anie.200805998

54. Cortajarena AL, Ortega D, Ocampo SM, García AG, Couleaud P, Miranda R, et al. Engineering Iron Oxide Nanoparticles for Clinical Settings. Nanobiomedicine. 2014;1:2. doi: 10.5772/58841

55. Gobbo OL, Zurek M, Tewes F, Ehrhardt C, Cremillieux Y. Manganese: a new contrast agent for lung imaging?. Contrast media \& molecular imaging. 2012;7:542-546. doi: 10.1002/cmmi.1483

56. Hilger I, Kaiser WA. Iron oxide-based nanostructures for MRI and magnetic hyperthermia. Nanomedicine-UK. 2012;7(9):1443-1459. doi:10.2217/nnm.12.112

57. Kumar A, Jena PK, Behera S, Lockey RF, Mohapatra S, Mohapatra S. Multifunctional magnetic nanoparticles for targeted delivery. Nanomedicine-Uk. 2010;6:64-69. doi:10.1016/j.nano.2009.04.002

58. Al-Jamal WT1, Al-Jamal KT, Tian B, Lacerda L, Bomans PH, Frederik PM, et al. Lipid-quantum dot bilayer vesicles enhance tumor cell uptake and retention in vitro and in vivo. ACS Nano. 2008;2(3):408-418. DOI: 10.1021/nn700176a

59. Al-Jamal WT, Kostarelos K. Liposomes: From a clinically established drug delivery system to a nanoparticle platform for theranostic nanomedicine. Acc Chem Res. 2011;44(10):1094-1104. DOI: $10.1021 / \operatorname{ar} 200105 p$

60. Leung SJ, Romanowski M. Light-activated content release from liposomes. Theranostics. 2012;2(10):1020-1036. DOI: 10.7150/ thno.4847

61. Nie Y, Ji L, Ding H, Xie L, Li L, He B, et al. Cholesterol derivativesbased charged liposomes for doxorubicin delivery: preparation, in vitro and in vivo characterization. Theranostics. 2012;2(11):10921103. DOI: $10.7150 /$ thno.4949

62. D Papahadjopoulos, T M Allen, A Gabizon, E Mayhew, K Matthay, S $\mathrm{K}$ Huang, et al. sterically stabilized liposomes - improvements in pharmacokinetics and antitumor therapeutic efficacy. Proc Natl Acad Sci USA. 1991;88(24):11460-11464.

63. Torchilin VP. Recent advances with liposomes as pharmaceutical carriers. Nat Rev Drug Discov. 2005;4(2):145-160. DOI: 10.1038/ $\operatorname{nrd} 1632$

64. Kataoka K, Harada A, Nagasaki Y. Block copolymer micelles for 
drug delivery: design, characterization and biological significance. Adv Drug Deliv Rev. 2001;47(1):113-131.

65. Mahmud A, Xiong XB, Aliabadi HM, Lavasanifar A. Polymeric micelles for drug targeting. J Drug Target. 2007;15(9):553-584.

66. Sawant RR1, Jhaveri AM, Koshkaryev A, Zhu L, Qureshi F, Torchilin VP. Targeted transferrin-modified polymeric micelles: enhanced efficacy in vitro and in vivo in ovarian carcinoma. Mol Pharm. 2014;11(2):375-381. DOI: 10.1021/mp300633f

67. Kumar R, Kulkarni A, Nagesha DK. et al. In vitro evaluation of theranostic polymeric micelles for imaging and drug delivery in cancer. Theranostics. 2012;2(7):714-722. doi: 10.7150/thno.3927

68. Liu L, Yong KT, Roy I, Law WC, Ye L, Liu J, et al. Bioconjugated pluronic triblock-copolymer micelle-encapsulated quantum dots for targeted imaging of cancer: in vitro and in vivo studies. Theranostics. 2012;2(7):705-713.

69. Mi Y, Liu Y, Feng SS. Formulation of docetaxel by folic acidconjugated $d$ - $\alpha$-tocopheryl polyethylene glycol succinate 2000 (Vitamin E TPGS(2k)) micelles for targeted and synergistic chemotherapy. Biomaterials. 2011;32(16):4058-4066. DOI: 10.1016/j.biomaterials.2011.02.022

70. Torchilin VP, Lukyanov AN, Gao Z, Sternberg BP. Immunomicelles: targeted pharmaceutical carriers for poorly soluble drugs. Proc Natl Acad Sci USA. 2003;100(10):6039-6044. DOI: 10.1073/ pnas.0931428100

71. Sailor MJ, Park JH. Hybrid nanoparticles for detection and treatment of cancer. Adv.Matt 2012;10:1-24.

72. Fahmy TM, Fong PM, Park J, Constable T, Saltzman WM. Nanosystems for simultaneous imaging and drug delivery to T Cells. AAPS J. 2007;9(2):E171-E180. DOI: 10.1208/aapsj0902019

73. Grünwald GK, Vetter A, Klutz K, Willhauck MJ, Schwenk N, Senekowitsch-Schmidtke R, et al. Systemic image-guided liver cancer radiovirotherapy using dendrimer-coated adenovirus encoding the sodium iodide symporter as theranostic gene. J Nucl Med. 2013;54(8):1450-1457. DOI: 10.2967/jnumed.112.115493

74. Jansen JF, de Brabander-van den Berg EM, Meijer EW. Encapsulation of guest molecules into a dendritic box. Science. 1994;266(5188):1226-1229. DOI: 10.1126/science.266.5188.1226

75. Müller RH, Rühl D, Runge $S$, Schulze-Forster $K$, Mehnert W.Cytotoxicity of solid lipid nanoparticles as a function of the lipid matrix and the surfactant. Pharm Res. 1997;14(4):458-462.

76. Wissing SA, Kayser 0, Müller RH. Solid lipid nanoparticles for parenteral drug delivery. Adv Drug Del Rev. 2004;56(9):12571272. DOI: 10.1016/j.addr.2003.12.002

77. Lammers T, Ulbrich K. HPMA copolymers: 30 years of advances. Adv Drug Del Rev. 2010;62(2):119-121. DOI: 10.1016/j. addr.2009.12.004

78. Kopecek J, Kopeckova P. HPMA copolymers: origins, early developments, present, and future. Adv Drug Del Rev. 2010;62(2):122-149. DOI: 10.1016/j.addr.2009.10.004

79. Nakamura H, Etrych T, Chytil P, Ohkubo M, Fang J, Ulbrich K, et al. Two step mechanisms of tumor selective delivery of $\mathrm{N}-(2-$ hydroxypropyl) methacrylamide copolymer conjugated with pirarubicin via an acid-cleavable linkage. J Control Release. 2014;174:81-87. DOI: 10.1016/j.jconrel.2013.11.011

80. Nayak TR, Zhang Y,Cai W. Cancer Theranostics with Carbon-Based Nanoplatforms. Cancer theranostics. 2014;347-361.

81. Hongjie Dai. Carbon nanotubes: synthesis, integration and properties, Acc Chem Res. 2002;35(12):1035-1044. DOI: 10.1021/ ar0101640

82. Gong H, Peng R, Liu Z. Carbon nanotubes for biomedical imaging: the recent advances. Adv Drug Deliv Rev 2013;65(15):1951-1963. Doi:10.1016/jaddr.2013.10.002

83. Hong $\mathrm{H}$, Gao T, Cai W. Molecular imaging with single walled carbon nanotubes. Nano Today 2009;4(3):252-261. DOI: 10.1016/j. nantod.2009.04.002

84. Das M, Datir SR, Singh RP, Jain S. Augmented anticancer activity of a targeted, intracellularly activatable, theranostic nanomedicine based a fluorescent and radiolabeled, methotrxatefolic acid-multiwalled carbon nanotube conjugate. Mol Pharm. 2013;10(7):2543-2557. DOI: 10.1021/mp300701e

85. Chen S, Hu, Smith EF, Pakatip R, Thorley AJ, Menzel R, et al. Aqueous cationic, anionic and non-ionic multi-walled carbon nanotubes, functionalized with minimal framework damage, for biomedical applications. Biomaterials. 2014, 35:4729-4762.

86. Accardo A, Tesauro D, Morelli G. Peptide-based targeting strategies for simultaneous imaging and therapy with nanovectors. Polymer journal 2013;45:481-493. DOI:10.1038/pj.2012.215

87. Wang $\mathrm{AZ}, \mathrm{Gu}$ F, Zhang L,Chan J, Radovic-Morino A, Shaikh MR , Farokhzad OC. Biofunctional targeted nanoparticles for therapeutic applications. Expert Opin Biol Ther. 2008;8:10631070. DOI: $10.1517 / 14712598.8 .8 .1063$

88. Nripen C, Shukla R, Katti KV, Kannan R. Gastrin releasingprotein receptor- specific gold nanorods: breast and prostate tumor-avid nanovectors for molecular imaging. Nanolett.2009;9(5):1798-1805. DOI: 10.1021/nl8037147

89. Zhang F, Huang X, Zhu L, Guo N, Niu G, Swierczewska M, et al. Noninvasive monitoring of orthotopic glioblastoma therapy response using RGD-conjugated iron oxide nanoparticles. Biomaterials. 2012;33(21):5414-5422. DOI: $10.1016 / \mathrm{j}$. biomaterials.2012.04.032

90. Murphy EA, Majeti BK, Barnes LA, Makale M, Weis SM, Lutu-Fuga $\mathrm{K}$, et al. Naoparticle-mediated drug delivery to tumor vasculature suppresses metastasis. PNAS. 2008;105:9343-9348. DOI: 10.1073/ pnas. 0803728105

91. He X, Na MH, Kim JS, Lee GY, Park JY, Hoffman AS, et al. A novel peptide probe for imaging and targeted delivery of liposomal doxorubicin in lung tumor. Mol.Pharmaceutics 2011;8:430-438. DOI: $10.1021 / \mathrm{mp} 100266 \mathrm{~g}$

92. Lim CK, Shin J, Lee YD, Kim J, Oh KS, Yuk SH, et al. Phthalocyanineaggregated polymeric nanoparticles as tumor-homing nearinfrared absorbers for photothermal therapy of cancer. Theranostics. 2012;2(9):871-879. DOI: 10.7150/thno.4133

93. Yang K, Hu L, Ma X, Ye S, Cheng L, Shi X, et al. Multimodal imaging fuided photothermal therapy using functionalized graphene 
nanosheets anchored with magnetic nanoparticles. Adv.Mater 2012;10(14):1868-1872, DOI:10.1002/ adma. 201104964

94. Zhang H, Huixia W, Wang J, Yang Y, Wu D, Zhang Y, et al. Graphene oxide-BaGdF5 nanocomposite for multimodal imaging and photothermal therapy. Biomaterials 2015;42:66-67.

95. Justin R, Tao K, Roman S, Chen D, Xu Y, Geng X, et al. Photoluminescent and superparamagnetic graphene oxide-iron oxide quantum dots for dual- modality imaging, drug delivery and photothermal therapy. Carbon 2016;97:54-70.

96. Liu TW, Huynh E, MacDonald T, Zheng G. Porphyrins for imaging, photodynamic therapy and photothermal therapy. Chapter 14. Cancer theranostics. 2014;229-254. DOI: 10.1016/B978-0-12407722-5-00014-1

97. Josefsen L, Boyle RW. Unique diagnostic and therapeutic role of porphyrins and phthalocyanins in photodynamic therapy, imaging and theranostics. Theranostics 2012;2(9):916-966. DOI: $10.7150 /$ thno.4571.

98. Wielder ME, Hone DC, Cook MJ, Handsley MM Gavrilovic J, Russel DA. Intracellular photodynamic therapy with photosensitizernanoparticle conjugates: cancer therapy using 'Trojan horse. Photochem Photobiol Sci. 2006;5:727-734. DOI: 10.1039/b602830f

99. Cheng Y, Meyers JD, Agnes RS, Doane TL, Kenney ME, Broome AM, et al. Addressing brain tumors with targeted gold nanoparticles: a new gold standard for hydrophobic drug delivery? Small. 2011;7(16):2301-2306. DOI: 10.1002/smll.201100628

100. Celli JP, Spring BQ, Rizvi I, Evans CL, Samkoe KS, Verma S, et al Imaging and photodynamic therapy: mechanisms, monitoring and optimization. Chem Rev. 2010;110(5):2795-2838. DOI: 10.1021/ cr900300p

101. Ethirajan M, Chen Y, Joshi P, Pandey RK. The role of porphyrin chemistry in tumour imaging and photodynamic therapy. Chem Soc Rev. 2011;40:340-362. DOI: 10.1039/B915149B

102. Cui SS, Yin DY, Chen YQ, Di YF, Chen HY, Ma YX, et al. Invivo targeted deep tissue photodynamic therapy based on near infra-red light triggered upconversion nanoconstruct. ACS Nano 2013;7:676688.

103. Garcia AM, Alarcon E, Munoz M, Scaiano JC, Edwards AM, Lissi E. Photophysical behavior and photodynamic activity of zinc phthalocyanines associated to liposomes. Photochem Photobiol Sci. 2011;10:507-514. DOI: 10.1039/c0pp00289e

104. Guo H,Quian HS,Idris NM, Zhang Y. singlet oxygen-induced apoptosis of cancer cells using upconversion fluorescent nanoparticles as a carrier of photosensitizer. Nanomedicine 2010;6(3):486-495. DOI: 10.1016/j.nano.2009.11.004

105. Lu HL, Syu WJ, Nishiama N, Kataoka K, Lai PS. Dendrimer phthalocyanine -encapsulated polymeric micelle-mediated photochemical internalization extends the efficacy of photodynamic therapy and overcome drug resistance in vivo. J Contolled Release 2011;155:458-464. DOI: 10.1016/j. jconrel.2011.06.005

106. Mitsunaga M, Ogawa M, Kosaka N, Rosenblum LT, Choyke PL, Kobayashi H. Cancer cell-selective invivo near infrared photoimmunotherapy targeting specific membrane molecules. Nat Med. 2011;17(12):1685-1691. DOI: 10.1038/nm.2554

107. Vivero-Escorto L, Elnagheeb M. Mesoporous silica nanoparticles loaded with cisplatin and phthalocyanin for combination chemotherapy and photodynamic therapy in vitro. Nanomaterials 2015;5(4):2302-2316. Doi: 10.3390/nano5042302.

108. Olena Taratula, Canan Schumann, Naleway MA, Pang AJ, Chon KJ, Taratula 0. A Multifunctional Theranostic Platform Based on Phthalocyanine-Loaded Dendrimer for Image-Guided Drug Delivery and Photodynamic Therapy. Molecular Pharmaceutics. 2013;10(10). DOI: 10.1021/mp400397t

109. Bruchez M, Moronne M, Gin P Weiss S, Alivisatos AP. Semiconductor nanocrystals as fluorescent biological labels. Science. 1998;281(5385):2013-2016 doi: 10.1126/science.281.5385.2013

110. Fu A, Gu W, Larabell C, Alivisatos AP. Semiconductor nanocrystals for biologic imaging. Currentopinion in neurobiology 2005;15:568575 doi:10.1016/j.conb.2005.08.004.

111. Walker CD, Chan CW. Quantum dots for traceable therapeutic delivery. Cancer Theranostics. 2014;393-417. DOI: 10.1016/B9780-12-407722-5-00021-9

112. Yong K-T, Roy I, Swihart MT, Prasad PN. Multifunctional nanoparticles as biocompatible targeted probes for human cancer diagnosis and therapy. J Mater Chem. 2009;19:4655-4672. D0I:10.1039/B817667C.

113. Cao L, Yang ST, Wang X, Luo PG, Liu JH, Sahu S, et al. Competitive performance of carbon "quantum" dots in optical bioimaging. Theranostics. 2012;2(3):295-301 doi:10.7150/thno.3912

114. Kim GB, Kim YP. Analysis of protease activity using quantum dots and resonance energy transfer. Theranostics. 2012;2(2):127-138. DOI:10.7150/thno.3476

115. Yong KT, Wang Y, Roy I, Rui H, Swihart MT, Law WC, et al. Preparation of quantum dot/drug nanoparticle formulations for traceable targeted delivery and therapy. Theranostics. 2012;2(7):681-694. doi:10.7150/thno.3692

116. Hu R, LawWC, Lin G. Ye L, Liu J, Jing Liu et al. PEGylated phospholipid micelle-encapsulated near-infrared PbS quantum dots for in vitro and in vivo bioimaging. Theranostics. 2012;2(7):723-733 doi:10.7150/thno. 4275

117. Zhang LW, Wen CJ, Suwayeh SA, Yen TC, Fang JY. Cisplatin and quantum dots encapsulated in liposomes as multifunctional nanocarriers for theranostic use in brain and skin. J Nanopart Res. 2012;14: 882, DOI: 10.1007/Si 1051-0120882-9

118. Santra S. The potential clinical impact of quantum dots. Nanomedicine (Lond). 2012;7(5):623-626. DOI: 10.2217/ nnm. 12.45

119. Zhu Y, Hong H, Xu ZP, Li Z, Cai W. Quantum dot-based nanoprobes for in vivo targeted imaging. Curr Mol Med. 2013;13(10):15491567.

120. Wu X1, Tian F, Zhao JX, Wu M. Evaluating pharmacokinetics and toxicity of luminescent quantum dots. Expert Opin Drug Metab Toxicol. 2013;9(10):1265-1277. DOI: $10.1517 / 17425255.2013 .807797$ 